\title{
Níveis de lisina digestível em rações para alevinos de tilápia-do-nilo
}

\author{
Sylvia Sanae Takishita ${ }^{1}$, Eduardo Arruda Teixeira Lanna ${ }^{2}$, Juarez Lopes Donzele ${ }^{2}$, Marcos \\ Antonio Delmondes Bomfim ${ }^{3}$, Moisés Quadros ${ }^{1}$, Maíra Paula de Sousa ${ }^{4}$
}

\author{
${ }_{1}$ Programa de Pós-graduação em Zootecnia - Departamento de Zootecnia/UFV. \\ 2 Universidade Federal de Viçosa/Departamento de Zootecnia. \\ ${ }^{3}$ Universidade Federal do Maranhão. \\ ${ }^{4}$ PETROBRAS/CENPES/PDEDS/BTA.
}

RESUMO - Avaliaram-se níveis de lisina digestível em rações para alevinos de tilápia-do-nilo (Oreochromis niloticus), linhagem tailandesa, com base no conceito de proteína ideal. Utilizaram-se 432 alevinos com peso inicial de 0,98 \pm 0,03 g, distribuídos em delineamento inteiramente casualizado, com 6 tratamentos, 6 repetições e 12 peixes por unidade experimental. Os tratamentos constaram de seis rações isoenergéticas (3.000 kcal de ED/kg de ração) e isoproteicas (39,14\% de PB) contendo 1,50; 1,66; 1,82; 1,98; 2,14 ou 2,30\% de lisina digestível. Foram avaliados o consumo de ração, o consumo de lisina digestível, o ganho de peso, a taxa de crescimento específico, a taxa de sobrevivência, a conversão alimentar, as taxas de deposição diária de proteína e gordura corporais, a composição química corporal (teores de umidade, proteína e gordura corporais) e a eficiência de retenção de nitrogênio. O consumo de lisina digestível, a conversão alimentar, a porcentagem de proteína corporal e a deposição de proteína corporal melhoraram de forma linear de acordo com o nível de lisina digestível. O modelo Linear Response Plateau foi o de melhor ajuste para consumo de ração, ganho de peso, taxa de crescimento específico e eficiência de retenção de nitrogênio e estimou em 2,06; 2,17; 2,14 e 2,12\%, respectivamente, os níveis de lisina digestível para melhorar cada um desses parâmetros. A exigência de lisina digestível e total em rações para alevinos de tilápia-do-nilo é, respectivamente, de $2,17 \%$ (0,723\%/Mcal de energia digestível) e de 2,32\% (0,773\%/Mcal de energia digestível) para atender às principais características de desempenho e de carcaça utilizando-se o conceito de proteína ideal na formulação das rações.

Palavras-chave: aminoácidos, nutrição proteica, Oreochromis niloticus, proteína ideal

\section{Digestible lysine level in feed for Nile tilapia fingerlings}

\begin{abstract}
The effect of digestible lysine levels was evaluated in diets for Nile tilapia fingerlings (Oreochromis niloticus), Thailand lineage, based on the ideal protein concept. Four hundred and thirty two Nile tilapia fingerlings with an initial body weight of $0.98 \pm 0.03 \mathrm{~g}$ were allotted in a randomized complete design, with six treatments, six replications per treatment and twelve fish per experimental unit. The treatments consisted of six isoenergetic (3.000 kcal of DE/kg feed) and isoproteic (39.14\% CP) diets with different levels of digestible lysine (1.50, 1.66, 1.82, 1.98, 2.14 and 2.30\%). Feed intake, digestible lysine intake, average weight gain, specific growth rate, survival rate, feed conversion, daily protein deposition rate, daily fat deposition rate, chemical body composition (moisture, protein and fat content) and nitrogen retention efficiency were evaluated. The different levels of lysine improved linearly the parameters of digestible lysine intake, feed conversion, body protein content and body protein deposition. The Linear Response Plateau model best fitted the parameters of feed consumption, average weight gain, specific growth rate and nitrogen retention efficiency, estimating at $2.06 \%, 2.17,2.14$ and $2.12 \%$ respectively, the level of digestible lysine to maximize each of the parameters. The digestible and total digestible lysine requirement for Nile tilapia fingerlings was $2.17 \%(0.723 \% / \mathrm{Mcal}$ of DE) and $2.32 \%$ (0.773\%/Mcal of DE), respectively, to meet the main performance parameters and carcass traits, when the ideal protein concept was used in diet formulation.
\end{abstract}

Key Words: aminoacids, ideal protein, Oreochromis niloticus, proteic nutrition

\section{Introdução}

A tilápia-do-nilo (Oreochromis niloticus) foi introduzida no Brasil há mais de 20 anos e atualmente é uma das espécies mais produzida em cativeiros no País. Tilápias alimentam-se dos níveis primários da cadeia trófica, aceitam grande variedade de alimentos e respondem com a mesma eficiência à ingestão de proteínas de origem vegetal e animal, características que conferem vantagens produtivas à espécie. Além disso, são resistentes a doenças, superpovoamentos e baixos teores de oxigênio dissolvido. 
Grande número dos estudos sobre exigências nutricionais para peixes tem abordado as exigências de proteínas e aminoácidos por serem os componentes mais caros das formulações. Além disso, em níveis excedentes às exigências dos animais, resultam em elevada excreção de nitrogênio, um dos principais responsáveis pela eutrofização do ambiente aquático (Furuya et al., 2001). Segundo Wilson \& Poe (1985), peixes não possuem exigência específica por proteína bruta, mas exigência por adequado balanceamento de aminoácidos essenciais e não-essenciais, que devem estar presentes em proporções adequadas e que podem ser obtidos pela combinação de ingredientes ou pela suplementação com aminoácidos sintéticos.

As rações utilizadas na aquicultura, além de atender às exigências nutricionais das espécies, devem proporcionar reduzidos excedentes de nutrientes visando diminuir os impactos negativos sobre os sistemas de criação e os ecossistemas aquáticos (Henry-Silva et al., 2006). A formulação de rações com base no conceito de proteína ideal pode ser uma estratégia eficiente para essas condições. As exigências de lisina para tilápia-do-nilo encontradas na literatura são diversas, com recomendações de 1,40 a 1,80\% de lisina total (Bomfim et al., 2006). Objetivou-se com este trabalho determinar a exigência de lisina digestível em rações para alevinos de tilápia-do-nilo com base no conceito de proteína ideal.

\section{Material e Métodos}

O experimento foi conduzido de abril a maio de 2007, no Laboratório de Nutrição de Peixes do Departamento de Zootecnia da Universidade Federal de Viçosa (UFV), localizado no município de Viçosa, Minas Gerais, e teve duração de 32 dias.

Foram utilizados 432 alevinos revertidos de tilápia-donilo (Oreochromis niloticus), linhagem tailandesa, com peso inicial de 0,98 $\pm 0,03 \mathrm{~g}$, em um experimento com delineamento inteiramente casualizado com 6 tratamentos ( 1,$50 ; 1,66 ; 1,82 ; 1,98 ; 2,14$ ou $2,30 \%$ de lisina digestível), 6 repetições e 12 peixes por unidade experimental.

Os alevinos foram mantidos em 36 aquários de polietileno com capacidade volumétrica de 150 litros e volume útil de 130 litros, dotados de sistemas individuais de aeração, abastecimento de água e escoamento de fundo disposto em sistema de recirculação e renovação mínima de água de $25 \%$ por dia.

A água de abastecimento dos aquários, proveniente do sistema de tratamento de água da Universidade Federal de Viçosa (UFV), foi previamente declorada e aquecida por resistências elétricas, com temperatura controlada por termostato. A temperatura da água foi mantida em torno de $28^{\circ} \mathrm{C}$ e monitorada diariamente, às $7 \mathrm{~h} 30$ e $17 \mathrm{~h} 30$, por meio de um termômetro eletrônico graduado de 0 a $50^{\circ} \mathrm{C}$. Os controles do $\mathrm{pH}$ e do teor de oxigênio dissolvido na água foram realizados a cada sete dias, respectivamente, utilizando-se potenciômetro e oxímetro.

A limpeza dos aquários foi realizada duas vezes por dia, para retirada das fezes por sifonagem, sempre após as leituras da temperatura da água. O fotoperíodo foi mantido em 12 horas de luz, por meio de iluminação proveniente de lâmpadas mistas, controlado por timer automático.

As dietas experimentais foram formuladas à base de milho, glúten de milho e farelo de soja e suplementadas com minerais e vitaminas para atender às exigências dos alevinos, de acordo com recomendações do NRC (1993).

As suplementações com L-lisina foram feitas em substituição ao ácido glutâmico, com base no equivalente proteico, para assegurar que todas as rações experimentais mantivessem o mesmo teor de proteína bruta. Foram feitas inclusões de amido em substituição ao óleo de soja para que as dietas experimentais mantivessem o mesmo teor de energia digestível. As rações foram suplementadas, quando necessário, com níveis crescentes de metionina+cistina, treonina, triptofano e isoleucina, mantendo-se constante em 66; 77; 23 e 64\% a relação entre esses aminoácidos e lisina na base digestível (Tabela 1). Dessa forma, a relação desses aminoácidos com a lisina foi mantida pelo menos três pontos percentuais acima daquelas estimadas a partir dos valores de exigência recomendados pelo NRC (1993). As composições percentuais e bromatológicas das dietas experimentais foram calculadas segundo Rostagno et al.(2005).

Os valores para aminoácidos digestíveis e fósforo disponível foram estimados com base nos coeficientes de digestibilidade dos ingredientes, de acordo com Rostagno et al. (2005), e de energia, de acordo com Pezzato et al. (2002).

As rações experimentais foram peletizadas e fornecidas diariamente, em seis refeições (às 8, 10, 12, 14, 16 e 18 h), em pequenas quantidades, com sucessivos repasses, a fim de possibilitar a ingestão máxima, sem perdas, até a aparente saciedade, reduzindo a possibilidade de lixiviações.

No início do período experimental, foram sacrificados 80 peixes, depois de anestesiados, para análise corporal. Ao final do experimento, foram selecionados oito animais por unidade experimental, com os pesos mais próximos ao peso médio da respectiva unidade.

As análises bromatológicas das rações e das amostras dos peixes foram realizadas no Laboratório de Nutrição Animal do Departamento de Zootecnia (LNA/DZO) da Universidade Federal de Viçosa - UFV, conforme 
Tabela 1 - Composição percentual e bromatológica das rações experimentais com base na matéria natural

\begin{tabular}{|c|c|c|c|c|c|c|}
\hline \multirow[t]{2}{*}{ Ingrediente (\%) } & \multicolumn{6}{|c|}{ Nível de lisina digestível (\%) } \\
\hline & 1,50 & 1,66 & 1,82 & 1,98 & 2,14 & 2,30 \\
\hline Farelo de soja & 50,091 & 50,091 & 50,091 & 50,091 & 50,091 & 50,091 \\
\hline Milho & 20,597 & 20,597 & 20,597 & 20,597 & 20,597 & 20,597 \\
\hline Óleo de soja & 0,349 & 0,314 & 0,258 & 0,181 & 0,104 & - \\
\hline Amido de milho & 0,452 & 0,591 & 0,793 & 1,017 & 1,240 & 1,500 \\
\hline L-lisina $\mathrm{HCl}-78,4 \%$ & 0,000 & 0,205 & 0,409 & 0,614 & 0,818 & 1,023 \\
\hline L-triptofano - 99\% & 0,000 & 0,020 & 0,058 & 0,096 & 0,133 & 0,171 \\
\hline L-isoleucina - 99\% & 0,000 & 0,000 & 0,000 & 0,000 & 0,000 & 0,059 \\
\hline Ácido glutâmico - 99\% & 2,844 & 2,500 & 1,939 & 1,316 & 0,692 & 0,000 \\
\hline Fosfato bicálcico & 2,978 & 2,978 & 2,978 & 2,978 & 2,978 & 2,978 \\
\hline Vitamina $C^{1}$ & 0,050 & 0,050 & 0,050 & 0,050 & 0,050 & 0,050 \\
\hline Suplemento vitamínico e mineral ${ }^{2}$ & 0,500 & 0,500 & 0,500 & 0,500 & 0,500 & 0,500 \\
\hline Proteína bruta (\%) & 39,14 & 39,14 & 39,14 & 39,14 & 39,14 & 39,14 \\
\hline Energia digestível (kcal/kg) & 3000,00 & 3000,00 & 3000,00 & 3000,00 & 3000,00 & 3000,00 \\
\hline Ácido linoleico (\%) & 1,28 & 1,26 & 1,23 & 1,19 & 1,15 & 1,09 \\
\hline Cálcio (\%) & 0,87 & 0,87 & 0,87 & 0,87 & 0,87 & 0,87 \\
\hline Fósforo disponível (\%) & 0,60 & 0,60 & 0,60 & 0,60 & 0,60 & 0,60 \\
\hline Sódio (\%) & 0,257 & 0,257 & 0,257 & 0,257 & 0,257 & 0,257 \\
\hline Lisina total $(\%)$ & 1,653 & 1,814 & 1,974 & 2,134 & 2,294 & 2,455 \\
\hline Lisina digestível (\%) & 1,500 & 1,660 & 1,820 & 1,980 & 2,140 & 2,300 \\
\hline Metionia + cistina digestível (\%) & 1,157 & 1,157 & 1,201 & 1,307 & 1,412 & 1,518 \\
\hline Treonina digestível (\%) & 1,264 & 1,278 & 1,401 & 1,525 & 1,648 & 1,771 \\
\hline Triptofano digestível (\%) & 0,362 & 0,382 & 0,419 & 0,455 & 0,492 & 0,529 \\
\hline Isoleucina digestível (\%) & 1,414 & 1,414 & 1,414 & 1,414 & 1,414 & 1,472 \\
\hline
\end{tabular}

${ }^{1}$ Vit. C: sal cálcica 2-monofosfato de ácido ascórbico, 42\% de princípio ativo.

${ }^{2}$ Composição por quilograma do produto: vit. A, $1.200 .000 \mathrm{UI}$; vit. $\mathrm{D}_{3}, 200.000 \mathrm{UI}$; vit. E, $1.200 \mathrm{mg}$; vit. $\mathrm{K}_{3}$, $2.400 \mathrm{mg}$; vit. $\mathrm{B}_{1}$, $4.800 \mathrm{mg}$; vit. $\mathrm{B}_{2}$, 4.800 mg; vit. $\mathrm{B}_{6}$, 4.800 mg; vit. $\mathrm{B}_{12}, 4.800 \mathrm{mg}$; vit. C, $48 \mathrm{~g}$; ácido fólico, $1.200 \mathrm{mg}$; pantotenato de cálcio, $12.000 \mathrm{mg}$; vit. C, $48.000 \mathrm{mg}$; biotina, $48 \mathrm{mg}$; cloreto de colina, 108 g; niacina, $24.000 \mathrm{mg}$ Fe, 50.000 mg; Cu, 3.000 mg; Mn, 20.000 mg; Zn, 30.000 mg; I, 100 mg; Co, 10 mg; Se, 100 mg.

procedimentos descritos por Silva \& Queiroz (2002), e a umidade corporal foi determinada pelo processo de liofilização.

Foram avaliados o consumo de ração, o consumo de lisina digestível, o ganho de peso, a taxa de crescimento específico, a taxa de sobrevivência, a conversão alimentar, as taxas de deposição diária de proteína e gordura corporais, a composição química corporal (teores de umidade, proteína e gordura corporais) e a eficiência de retenção de nitrogênio.

Para determinação da taxa de crescimento específico (TCE), foi empregada a equação abaixo, utilizando-se transformações logarítmicas.

$\mathrm{TCE}=\log$ natural do peso final $(\mathrm{g})-\log$ natural do peso inicial $(\mathrm{g}) \times 100$

Período experimental (dias)

As deposições diárias de proteína e de gordura corporais foram calculadas pela diferença da proteína ou da gordura corporal final e inicial, respectivamente, em mg, dividida pelo período experimental (dias).

A eficiência de retenção de nitrogênio foi expressa em porcentagem, e calculada pela diferença do nitrogênio corporal final e inicial, dividido pelo nitrogênio total consumido, multiplicado por 100.

As análises estatísticas foram realizadas utilizando-se o programa SAEG - Sistema de Análises Estatísticas e Genéticas ( UFV, 1997). Os dados foram interpretados por meio de análises de regressão em nível de 5\% de probabilidade. Os efeitos dos níveis de lisina digestível foram analisados mediante o uso dos modelos de regressão linear, quadrático ou descontínuo Linear Response Plateau (LRP), conforme o melhor ajustamento obtido para cada variável.

\section{Resultados e Discussão}

Com o sistema de abastecimento de água e de aeração utilizado durante a condução do experimento os valores dos parâmetros de qualidade de água obtidos foram de $28,1 \pm 0,70^{\circ} \mathrm{C}$ para temperatura, de $6,80 \pm 0,30$ para o $\mathrm{pH}$, 6,0 $\pm 0,40$ ppm para o oxigênio dissolvido. Esses valores encontram-se dentro da faixa recomendada para a criação 
da espécie estudada, que é de $27^{\circ} \mathrm{C}$ a $32^{\circ} \mathrm{C}$ para temperatura da água, de 6,5 a 8 para pH, e acima de 4 ppm oxigênio, segundo Kubitza (2000).

O consumo de ração aumentou $(\mathrm{P}<0,05)$ de forma linear de acordo com o aumento na concentração de lisina digestível na dieta (Tabela 2). Apesar desse efeito linear, o modelo Linear Response Plateau (LRP) foi o que melhor se ajustou aos dados de consumo de ração e estimou em 2,06\% o nível de lisina digestível a partir do qual ocorreu um platô (Figura 1), correspondente a consumo diário estimado de 6,28 mg de lisina digestível.

Resultados semelhantes foram obtidos por Bomfim et al. (2006) em tilápias-do-nilo e Encarnação et al. (2004) em truta arco-íris. Esses autores observaram resposta linear no consumo de ração pelos peixes atribuída ao incremento de lisina digestível na dieta. Os resultados assemelham-se também aos obtidos por Furuya et al. (2006) ao estudarem os efeitos dos níveis de lisina na alimentação de juvenis de tilápia-do-nilo, e por Furuya et al. (2004) ao avaliarem o aumento dos níveis de lisina em dietas para tilápias em terminação, que obtiveram aumento no consumo de ração como resposta aos incrementos do aminoácido na dieta.

O aumento no consumo de ração ocasionado pelos níveis de lisina digestível é um indício de que melhores balanceamentos de aminoácidos na dieta estimulam o consumo de ração dos alevinos. Os resultados dos diferentes estudos evidenciaram que a influência da melhoria do balanceamento de aminoácidos sobre o consumo voluntário de alimento dos peixes não depende da fase de crescimento.

Perfis aminoacídicos desbalanceados na dieta podem ocasionar redução no consumo de ração e reduzir a eficiência de utilização de aminoácidos essenciais (Bureau \& Encarnação, 2006). Confirmando essa proposição, Yamamoto et al. (2000) verificaram que, quando se permite livre seleção das rações, a truta arco-íris prefere dietas com perfil de aminoácidos essenciais adequadamente balanceado.

Os níveis de lisina digestível da dieta tiveram efeito $(\mathrm{P}<0,01)$ sobre o consumo de lisina digestível dos alevinos, que aumentou de forma linear segundo a equação $\hat{\mathrm{Y}}=-32,4514+113,413 \mathrm{X}\left(\mathrm{r}^{2}=0,99\right)$. O resultado obtido neste estudo assemelha-se ao observado por Bomfim et al. (2006), que verificaram aumento no consumo de lisina digestível conforme elevaram os níveis de lisina digestível da dieta. $\mathrm{O}$ aumento linear do consumo de lisina digestível pode ser atribuído ao aumento da concentração de lisina digestível nas rações associado ao consumo de ração pelos peixes, que foi estimulado pelo melhor balanceamento de aminoácidos.

Não foi observado efeito $(\mathrm{P}>0,05)$ dos níveis de lisina digestível nas rações sobre a taxa de sobrevivência dos alevinos. Os níveis de lisina digestível influenciaram $(\mathrm{P}<0,05)$ o ganho de peso dos alevinos, que aumentou de forma linear. Entretanto, o LRP foi o modelo de melhor ajuste para esse parâmetro e estimou em 2,17\% o nível de lisina a partir do qual ocorreu um platô (Figura 2), correspondente a um consumo diário estimado de 6,67 mg de lisina digestível.

O aumento no ganho de peso corrobora os resultados obtidos por Bomfim et al. (2006), que verificaram aumento linear nos valores desse parâmetro ao trabalharem com alevinos tilápia-do-nilo submetidos às mesmas condições experimentais deste estudo. Os resultados obtidos neste estudo assemelham-se também aos obtidos por Encaranção

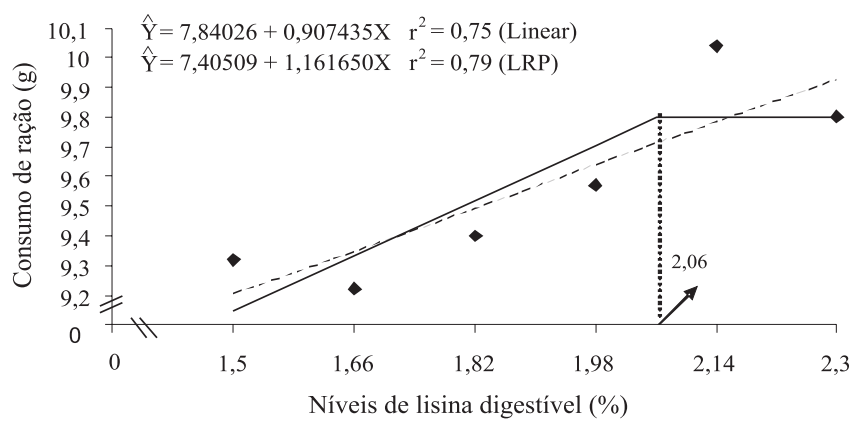

Figura 1 - Consumo de ração por alevinos de tilápia-do-nilo mantidos com rações com diversos níveis de lisina digestível.

Tabela 2 - Desempenho de alevinos de tilápia-do-nilo alimentados com rações com diversos níveis de lisina digestível

\begin{tabular}{|c|c|c|c|c|c|c|c|}
\hline \multirow[t]{2}{*}{ Parâmetro } & \multicolumn{6}{|c|}{ Nível de lisina digestível (\%) } & \multirow[t]{2}{*}{ CV (\%) } \\
\hline & 1,50 & 1,66 & 1,82 & 1,98 & 2,14 & 2,30 & \\
\hline Peso inicial (g) & 0,99 & 0,99 & 0,98 & 0,97 & 0,98 & 0,99 & 2,80 \\
\hline Consumo de ração (g) & 9,32 & 9,22 & 9,40 & 9,57 & 10,04 & 9,80 & 4,14 \\
\hline Ganho de peso (g) & 10,11 & 10,29 & 10,50 & 10,75 & 11,67 & 11,50 & 5,74 \\
\hline Conversão alimentar (g/g) & 0,92 & 0,90 & 0,90 & 0,89 & 0,86 & 0,85 & 4,45 \\
\hline Taxa de crescimento específico (\%/dia) & 7,56 & 7,60 & 7,69 & 7,78 & 7,97 & 7,93 & 2,29 \\
\hline
\end{tabular}

CV - coeficiente de variação. 


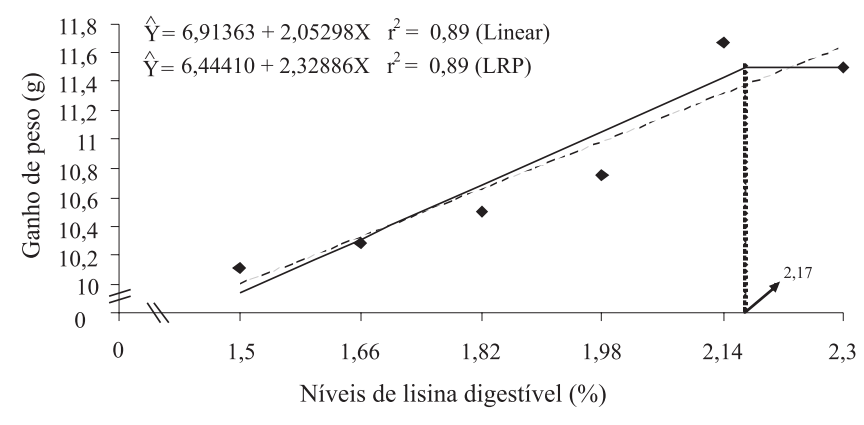

Figura 2 - Ganho de peso em alevinos de tilápia-do-nilo mantidos com rações com diversos níveis de lisina digestível.

et al. (2004), que verificaram aumento linear no ganho de peso de truta arco-íris na fase de crescimento como resposta ao aumento dos níveis de lisina digestível na dieta.

Contudo, o valor de exigência estimado para o ganho de peso é superior ao encontrado por Santiago \& Lovell (1988), de 1,43\% de lisina total, ao avaliarem juvenis de tilápia, e aos resultados obtidos por Furuya et al. (2004) e Furuya et al. (2006), que estimaram o valor de $1,42 \%$ de lisina total no primeiro estudo quando trabalharam com tilápias na fase de terminação, e em 1,56\% o nível de lisina digestível no segundo estudo, quando trabalharam com juvenis da mesma espécie. O valor de exigência obtido neste estudo é também superior ao encontrado por Bomfim et al. (2006), que estimaram em $1,70 \%$ de lisina digestível como o nível mínimo para obter o melhor desempenho em ganho de peso.

As diferenças entre os resultados podem estar relacionadas a fatores como espécie, linhagem de tilápias utilizada ou fase de crescimento analisada. Linhagens de peixes com maior capacidade de crescimento apresentam maior exigência de aminoácidos digestíveis que as de menor capacidade de crescimento (Hauler \& Carter, 2001).

Tilápias-tailandesas apresentam maior capacidade de ganho de peso diário em relação a tilápias-comuns (Boscolo et al., 2002). De forma semelhante, peixes na fase inicial (larvas e alevinos) apresentam elevada taxa de crescimento, que está diretamente relacionada à deposição de tecido muscular. De acordo com Baldisserotto (2002), larvas e alevinos possuem elevadas taxas metabólicas em comparação a peixes em crescimento e terminação, o que implica maiores taxas de crescimento dos animais jovens. Além disso, o custo energético de síntese proteica diminui conforme aumenta a taxa de crescimento.

As diferenças entre os resultados podem estar relacionadas ainda a fatores como composição das rações (purificadas, semipurificadas ou práticas) e a temperatura da água utilizada nos estudos.
Rações purificadas têm reconhecidamente menor aceitabilidade pelos peixes, por serem menos palatáveis que as rações práticas, o que acarreta menores ganhos de peso, eficiência alimentar e, consequentemente, exigência de lisina digestível na dieta, em comparação a rações práticas (Griffin et al., 1992).

A temperatura da água também influencia o metabolismo dos peixes, afetando seu desempenho (Moura et al., 2007); variações na temperatura da água, além de alterar o metabolismo dos peixes, pode também alterar a absorção de nutrientes (Baldisserotto, 2002). Segundo Kubitza (2000), temperaturas acima de $32^{\circ} \mathrm{C}$ e abaixo de $27^{\circ} \mathrm{C}$ reduzem o apetite e o crescimento de tilápias, portanto, as temperaturas abaixo das médias recomendadas para a espécie podem ser responsáveis por estimativas de exigências nutricionais subestimadas, uma vez que cada espécie de peixe possui uma faixa de temperatura na qual expressam maior potencial de crescimento.

A elevação dos níveis de lisina digestível na dieta resultou em melhoria linear $(\mathrm{P}<0,01)$ da conversão alimentar, conforme a equação $\hat{Y}=1,05138-0,086996 X\left(r^{2}=0,95\right)$. A melhoria linear da conversão alimentar com o aumento dos níveis de lisina digestível na dieta assemelha-se aos resultados dos estudos conduzidos por Bomfim et al. (2006), com conversão alimentar média de 1,19 ao trabalharem com alevinos de tilápia-do-nilo e por Furuya et al. (2006) com conversão alimentar média de 1,60 ao trabalharem com juvenis da mesma espécie.

A taxa de crescimento específico aumentou de forma linear ( $\mathrm{P}<0,01)$ com a variação nos níveis de lisina digestível, porém o LRP foi o modelo de melhor ajuste para esse parâmetro, estimando em 2,14\% o nível de lisina a partir do qual ocorreu um platô (Figura 3), correspondente a um consumo diário estimado de 6,57 mg de lisina.digestível.

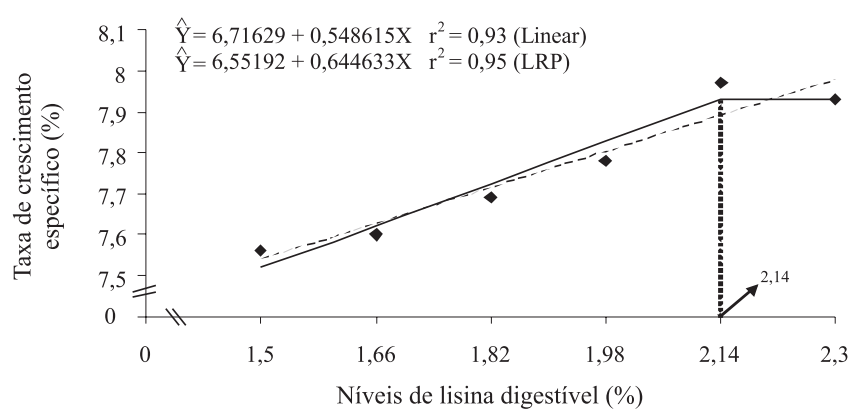

Figura 3 - Crescimento específico de alevinos de tilápia-do-nilo mantidos com rações com diversos níveis de lisina digestível. 
Os resultados de taxa de crescimento específico assemelham-se aos observados por Bomfim et al. (2006), que verificaram aumento linear desse parâmetro em alevinos de tilápia-do-nilo decorrente dos níveis de lisina digestível na dieta.

A taxa de crescimento específico médio de 7,9\% ao dia obtida pelos peixes alimentados com o maior nível de lisina testado assemelha-se àquela de $7,8 \%$ observada por Lanna et al. (2005) ao avaliarem a frequência de alimentação para alevinos de tilápia-do-nilo, e foi inferior à de 8,9\% ao dia obtida por Bomfim et al. (2006) em animais na mesma categoria de peso, porém com menor período experimental que o utilizado no presente estudo.

O aumento nos teores de lisina digestível da ração não influenciou $(\mathrm{P}>0,05)$ o teor de umidade e a porcentagem de gordura corporal dos peixes, como também não afetou $(\mathrm{P}>0,05)$ a deposição de gordura corporal (Tabela 3$)$. Esses resultados diferem dos encontrados por Bomfim et al. (2006), que relataram aumento linear dos valores obtidos para deposição de gordura corporal e redução do teor de umidade corporal, e dos resultados obtidos por Encarnação et al. (2006), que verificaram aumento no teor de gordura da carcaça de trutas arco-íris devido ao aumento dos níveis de lisina na dieta. Entretanto, assemelham-se aos observados por Furuya et al. (2006), que não observaram efeito dos níveis de lisina nas rações na porcentagem de gordura na carcaça.

Houve efeito $(\mathrm{P}<0,05)$ dos níveis de lisina digestível sobre a porcentagem de proteína corporal dos peixes, que aumentou de forma linear, de acordo com a equação $\hat{Y}=$ $9,37139+0,848736 \mathrm{X}\left(\mathrm{r}^{2}=0,79\right)$.

Os resultados de porcentagem de proteína corporal corroboram os estudos de Furuya et al. (2006), que verificaram aumento linear dos níveis de lisina digestível sobre a composição de proteína bruta corporal de juvenis de tilápiado-nilo. De maneira semelhante, Bomfim et al. (2006) verificaram aumento linear no teor de proteína corporal como resposta ao incremento de lisina digestível nas rações ao trabalharem com animais de mesma categoria de peso e linhagem.
Comparando o desempenho de juvenis de truta arcoíris alimentados com rações contendo 1,50 e 2,00\% de lisina digestível, Encarnação et al. (2006) obtiveram maior teor de proteína na carcaça de peixes alimentados com dietas com maior nível de lisina digestível.

A deposição de proteína corporal melhorou de forma linear $(\mathrm{P}<0,01)$ de acordo com o aumento dos níveis de lisina digestível na dieta, segundo a equação $\hat{Y}=18,4132+$ $10,09080 X\left(r^{2}=0,91\right)$. Resultado semelhante foi verificado por Bomfim et al. (2006) em tilápias e por El-Haroun \& Bureau (2006) em truta arco-íris. Estes resultados assemelham-se também aos obtidos por Encarnação et al. (2006) e Encarnação et al. (2004), que relataram aumento na deposição de proteína devido à adição de lisina em dietas para truta arco-íris.

A eficiência de retenção de nitrogênio teve aumento linear $(\mathrm{P}<0,01)$ de acordo com os níveis de lisina digestível na dieta. Entretanto, o LRP foi o modelo de melhor ajuste para os dados deste parâmetro, e estimou em 2,12\% o nível de lisina digestível (Figura 4), correspondente a um consumo diário de 6,50 mg de lisina digestível.

Os resultados de eficiência de retenção de nitrogênio corroboram os estudos de Furuya et al. (2006), que verificaram em juvenis de tilápia-do-nilo aumento linear

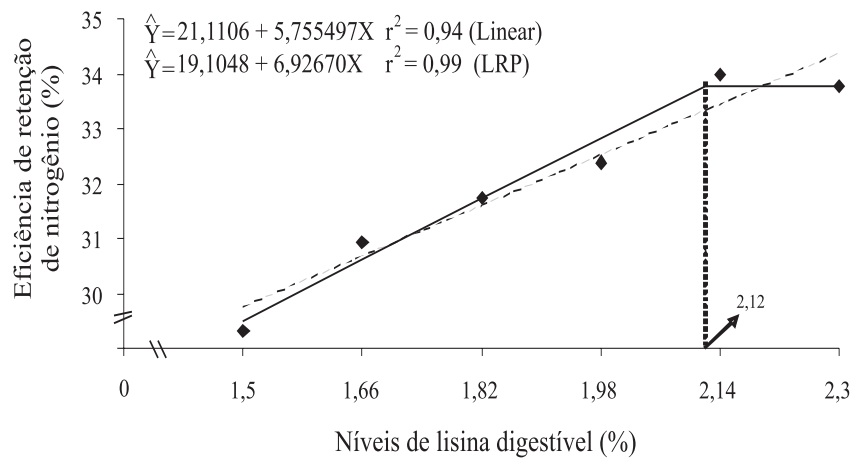

Figura 4 - Eficiência de retenção de nitrogênio em alevinos de tilápia-do-nilo alimentados com rações com diversos níveis de lisina digestível.

Tabela 3 - Composição corporal, deposições diárias de proteína e gordura corporais e eficiência de retenção de nitrogênio em alevinos de tilápia-do-nilo alimentados com rações com diversos níveis de lisina digestível

\begin{tabular}{|c|c|c|c|c|c|c|c|c|}
\hline \multirow[t]{2}{*}{ Parâmetro } & \multicolumn{7}{|c|}{ Nível de lisina digestível (\%) } & \multirow[t]{2}{*}{ CV $(\%$} \\
\hline & Inicial & 1,50 & 1,66 & 1,82 & 1,94 & 2,14 & 2,30 & \\
\hline Umidade corporal (\%) & 78,21 & 77,06 & 77,07 & 76,81 & 76,88 & 76,86 & 76,88 & 0,66 \\
\hline Porcentagem de gordura corporal & 7,33 & 5,20 & 5,24 & 5,85 & 5,69 & 5,02 & 5,01 & 18,28 \\
\hline Porcentagem de proteína corporal & 9,73 & 10,55 & 10,73 & 11,00 & 11,16 & 11,29 & 11,14 & 4,42 \\
\hline Deposição de gordura corporal (mg/dia) & - & 15,85 & 16,21 & 18,73 & 18,47 & 17,62 & 17,30 & 21,27 \\
\hline Deposição de proteína corporal (mg/dia) & - & 33,67 & 34,85 & 36,50 & 37,88 & 41,74 & 40,47 & 7,25 \\
\hline Eficiência de retenção de nitrogênio (\%) & - & 29,32 & 30,90 & 31,73 & 32,36 & 33,97 & 33,76 & 5,42 \\
\hline
\end{tabular}

CV - coeficiente de variação. 
da retenção de nitrogênio de acordo com os níveis de lisina digestível da ração. De maneira semelhante, Bomfim et al. (2006), ao trabalharem com animais de mesma categoria de peso e linhagem, verificaram aumento linear nesse parâmetro como resposta ao nível de lisina digestível nas rações.

\section{Conclusões}

As exigências de lisina digestível e total para alevinos de tilápia-do-nilo são de 2,17 e 2,32\% (0,723\% e 0,773\%/Mcal de energia digestível), correspondentes a consumos diários de 6,67 mg de lisina digestível e 7,21 mg de lisina total, para atender aos principais parâmetros de desempenho (ganho de peso, taxa de crescimento específico e consumo de ração) e às características de carcaça (eficiência de retenção de nitrogênio) utilizando-se o conceito de proteína ideal na formulação das rações experimentais.

\section{Agradecimentos}

À Ajinomoto Biolatina, pela concessão dos aminoácidos sintéticos. À Polinutri Alimentos, pela concessão do premix vitamínico e mineral. À Fapemig, pela participação no financiamento do projeto.

\section{Literatura Citada}

BALDISSEROTTO, B. Fisiologia de peixes aplicada à piscicultura. Santa Maria: Editora da UFSM, 2002. 212p.

BOMFIM, M.A.D.; LANNA, E.T.A.; DONZELE, J.L. et al. Níveis de Lisina digestível, com base no conceito de proteína ideal, em dietas para alevinos de tilápia do Nilo. In: REUNIÃO ANUAL DA SOCIEDADE BRASILEIRA DE ZOOTECNIA, 43., 2006, João Pessoa. Anais... São Paulo: Sociedade Brasileira de Zootecnia/Macromedia, [2006]. (CD-ROM).

BOSCOLO, W.R.; HAYASHI, C.; MEURER, F. Desempenho e características de carcaça de machos revertidos de tilápias do Nilo (Oreochromis niloticus, L.), linhagens tailandesa e comum, nas fases inicial e crescimento. Revista Brasileira de Zootecnia, v.31, n.2, p.539-545, 2002.

BUREAU, D.P.; ENCARNAÇÃO, P.M. Adequately defining the amino acid requirements of fish: the case example of lysine. In: SIMPOSIUM INTERNACIONAL DE NUTRICIÓN ACUÍCOLA; AVANCES EN NUTRICIÓN ACUÍCOLA, 8., 2006, Monterrey. Anais... Monterrey, 2006. p.29-54.

ENCARNAÇÃO, P.; LANGE, C.; BUREAU, D.P. Diet energy source affects lysine utilization for protein deposition in rainbow trout (Oncorhynchus mykiss). Aquaculture, v.261, p.1371-1381, 2006.

EL-HAROUN, E.R.; BUREAU, D.P. Comparison of the bioavailability of lysine in blood meals of various origins to that of L-lysine $\mathrm{HCl}$ for rainbow trout (Oncorhynchus mykiss). Aquaculture, v.262, p.402-409, 2006.
ENCARNAÇÃO, P.; LANGE, C.; RODEHUTSCORD, M. et al. Diet digestible energy content affects lysine utilization, but not dietary lysine requirements of rainbow trout (Oncorhynchus mykiss) for maximum growth. Aquaculture, v.235, p.569-586, 2004.

FURUYA, W.M.; SANTOS, V.G.; SILVA, L.C.R. et al. Exigências de lisina digestível para juvenis de tilápia-do-nilo. Revista Brasileira de Zootecnia, v.35, n.3, p.937-942, 2006 (supl.).

FURUYA, W.M.; BOTARO, D.; NEVES, P.R. et al. Exigência de lisina pela tilápia do Nilo na fase de terminação. Ciência Rural, v.34, n.5, p.1571-1577, 2004.

FURUYA, W.M; PEZZATO, L.E.; PEZZATO, A.C. et al. Coeficientes de digestibilidade e valores de aminoácidos digestíveis de alguns ingredientes para tilápia do Nilo (Oreochromis niloticus). Revista Brasileira de Zootecnia, v.30, n.4, p.1143-1149, 2001.

GRIFFIN, M.E.; BROWN, P.B.; GRANT, A.L. The dietary lysine requirement of juvenile hybrid striped bass. Journal of Nutrition, v.22, p.1332-1337, 1992.

HAULER, R.; CARTER, C. Reevaluation of the quantitative dietary lysine requirement of fish. Review in Fisheries Science, v.9, p.133-163, 2001.

HENRY-SILVA, G.G.; CAMARGO, A.F.M.; PEZZATO, L.E. Digestibilidade aparente de macrófitas aquáticas pela tilápiado-nilo (Oreochromis niloticus) e qualidade da água em relação às concentrações de nutrientes. Revista Brasileira de Zootecnia, v.35, n.3, p.641-647, 2006.

KUBITZA, F. Tilápia: tecnologia e planejamento na produção comercial. Jundiaí: Fernando Kubitza. 2000. 285p.

LANNA, E.A.T.; QUADROS, M.; BOMFIM, M.A.D. et al. Freqüência de alimentação em alevinos de tilápia do Nilo (Oreochromis niloticus) utilizando dietas de baixo teor proteico suplementadas com aminoácidos - resultados preliminares. In: REUNIÃO ANUAL DA SOCIEDADE BRASILEIRA DE ZOOTECNIA, 42., 2005, Goiânia. Anais... São Paulo: Sociedade Brasileira de Zootecnia/Macromedia, [2005]. (CD-ROM).

MOURA, G.S.; OLIVEIRA, M.G.A.; LANNA, E.T.A. et al. Desempenho e atividade de amilase em tilápias-do-nilo submetidas a diferentes temperaturas. Pesquisa Agropecuária Brasileira, v.42, n.11, p.1609-1615, 2007.

NATIONAL RESEARCH COUNCIL - NRC. Nutrient requirement of fish, Washington, D.C.: National Academy of Science, 1993. $105 p$.

PEZZATO, L.E.; MIRANDA, E.C.; BARROS, M.M. et al. Digestibilidade aparente de ingredientes pela tilápia do Nilo (Oreochromis niloticus). Revista Brasileira de Zootecnia, v.31, n.4, p.1595-1604, 2002.

ROSTAGNO, R.S.; ALBINO, L.F.T.; DONZELE, J.L. et al. Tabelas brasileiras para aves e suínos - composição de alimentos e exigências nutricionais. 2.ed. Viçosa, MG: Universidade Federal de Viçosa, 2005. 186p.

SANTIAGO, C.B.; LOVELL, R.T. Amino acid requirements for growth of Nile tilapia. Journal of Nutrition, v.118, p.1540-1546, 1988.

SILVA, D.J.; QUEIROZ, A.C. Análise de alimentos (métodos químicos e biológicos). 3.ed. Viçosa, MG: Universidade Federal de Viçosa, 2002. 235p.

UNIVERSIDADE FEDERAL DE VIÇOSA - UFV. Sistemas de Análises Estatísticas e Genéticas - SAEG. Versão 8.0. Viçosa, MG, 1997. 142p.

WILSON, R.P.; POE, W.E. Relationship of whole body and egg essential amino acid patterns to amino acid requirement patterns in channel catfish, Ictalurus punctatus. Comparative Biochemistry and Physiology, v.80B, n.2, p.385-388, 1985.

YAMAMOTO, T.; SHIMA, T.; FURUITA, H. et al. Self-selection of diets with different amino acid profiles by rainbow trout (Oncorhynchus mykiss). Aquaculture, v.187, p.375-386, 2000. 